\title{
A Photovoltaic based DC/AC Single-Phase Pure Sine wave Inverter
}

\author{
Sudhir $\mathbf{P}^{1}$, Swathi Hatwar ${ }^{2}$ \\ PG Scholar, Department EEE, NMAMIT, Nitte, India ${ }^{1}$ \\ Assistant Professor, Department of EEE, NMAMIT, Nitte, India ${ }^{2}$
}

\begin{abstract}
Solar photovoltaic energy is a booming industry in power generation sector. The DC-AC power converter plays a major role in photovoltaic conversion independent of PV module topology. In this paper, a single phase full bridge converter along with H-bridge inverter is simulated using MATLAB/Simulink. An intermediary High-frequency step-up transformer is used to step up the low voltage PV panel output to the mains AC supply voltage. The circuit has a total harmonic distortion below 5\% at steady state. Perturb and Observe MPPT is used at the full bridge converter side to control the duty cycle and Sinusoidal Pulse Width Modulation is used to control the switching at H-Bridge inverter side. The distortion at the output side is minimized by employing a suitable filter to attain better performance of the inverter.
\end{abstract}

Keywords: Solar Photovoltaic (PV); Full-Bridge DC-DC Converter; High-Frequency step-up transformer; SinglePhase H-Bridge pure sine-wave inverter; Sinusoidal Pulse Width Modulation (SPWM); Power Electronics.

\section{INTRODUCTION}

Solar PV based energy is gaining popularity because of its simplicity, availability and relatively low maintenance. Solar PV systems can meet large energy requirements at low cost with proper design and implementation in places where a lot of sunlight is received.

Both the converter and inverter circuits play a major role in PV power conversion systems. Usually, the general topology for a PV based power conversion system is a boost converter followed by an H-Bridge inverter [1]. PV converters are classified into Grid connected and Standalone power generation systems [2]. The main objective here is to build a standalone inverter while providing pure sine wave output and reduced harmonic distortion.

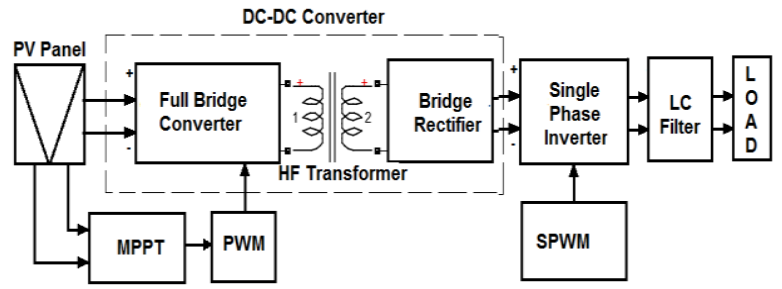

Fig 1: Block diagram of Photovoltaic Inverter with Full bridge converter

Fig 1 shows the block diagram of the proposed system. The system consists of a Full Bridge DC to DC Converter, High-frequency step-up transformer, and an H-Bridge Inverter. The inverter is controlled by unipolar SPWM technique [3].A passive low pass LC Filter is connected to the output of the inverter in order to reduce harmonic distortions. Perturb and Observe MPPT Technique [4] is used to extract the maximum possible power from panel output thus improving the overall efficiency of the system.

\section{SYSTEM DETAILS}

\section{A. Photovoltaic panel}

A PV cell is the smallest unit which transforms solar energy into electrical energy. Group of PV cells forms a module or a panel. Cells are connected in series and parallel combinations within the module to obtain panel rated voltage and current.

Modules can be connected in series or parallel combination to obtain required current and voltage. Thus connected modules are called as Strings. In order to generate several kilowatts of energy, there may be hundreds or thousands of Strings within a solar power generating station.

A Solar PV panel always produces DC power at the output. Various mathematical modeling exists to describe the PV panel equivalent circuit [5]. The current output of the panel depends on Solar Irradiation and temperature. The current- voltage relationship (I-V Curve) and the power-voltage relationship ( $\mathrm{P}-\mathrm{V}$ curve) play a key role in determining the PV panel characteristics and the power output of the panel. Both are non-linear curves and vary with the temperature and irradiation.Fig 3 shows the PV Panel characteristics for different values of Irradiations. 
PV Panel Characteristics for different Irradiations
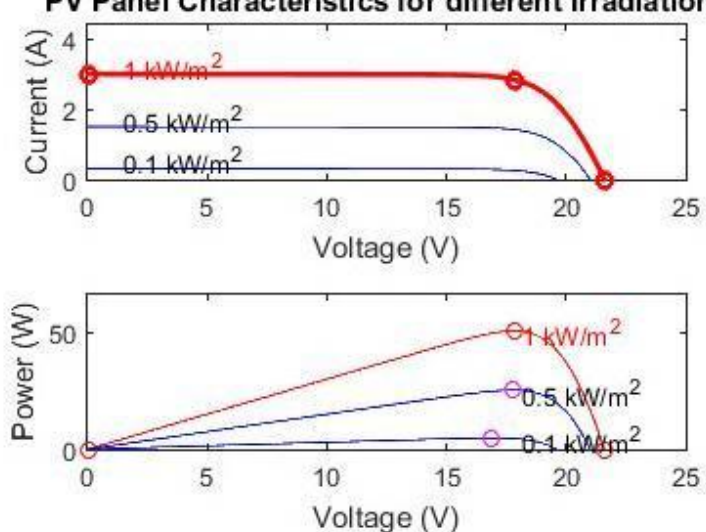

Fig 3: PV Panel Characteristics for different Irradiations

B. Perturb and Observe Algorithm

In order to obtain the maximum power output from the module, various MPPT Algorithms can be implemented. Because of its simplicity, $\mathrm{P} \& \mathrm{O}$ is the most commonly and widely used MPPT algorithm.

The $\mathrm{P} \& \mathrm{O}$ algorithm is called as the hill climbing algorithm because the curve is rising $(\mathrm{dP} / \mathrm{dV}>0)$ on the left and the falling $(\mathrm{dP} / \mathrm{dV}<0)$ on the right side of the $\mathrm{P}-\mathrm{V}$ characteristics.

The P\&O Algorithm involves the process of modifying the output voltage of the DC link between the array and the converter by perturbing the duty cycle. The sign of the last perturbation and the corresponding change in power is used to decide the next perturbation.

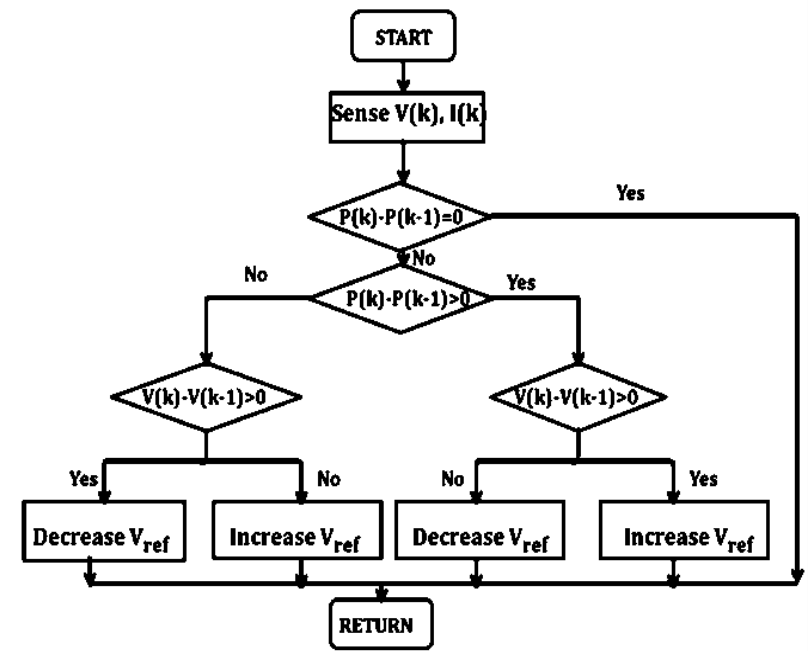

Fig 4: Perturb and Observe Algorithm reached. The operating point always oscillates around the MPP.

\section{DC-DC Converter}

The DC to DC Converter in this circuit consists of a full bridge converter, a High-frequency step-uptransformer, and a diode bridge. A full bridge converter consists of four MOSFET switches as shown in fig 5. These switches are controlled by PWM pulses. The P\&O MPPT determines the value of duty ratio. The Full bridge converter converts the continuous DC output voltage of the PV Panel into pulses of high frequency $(40 \mathrm{kHz})$ by the switching action of the MOSFET switches. The high-frequency switching reduces the overall size and weight of the transformer. The primary winding (LV) of the High-frequency step-up transformer is connected to the full bridge converter.

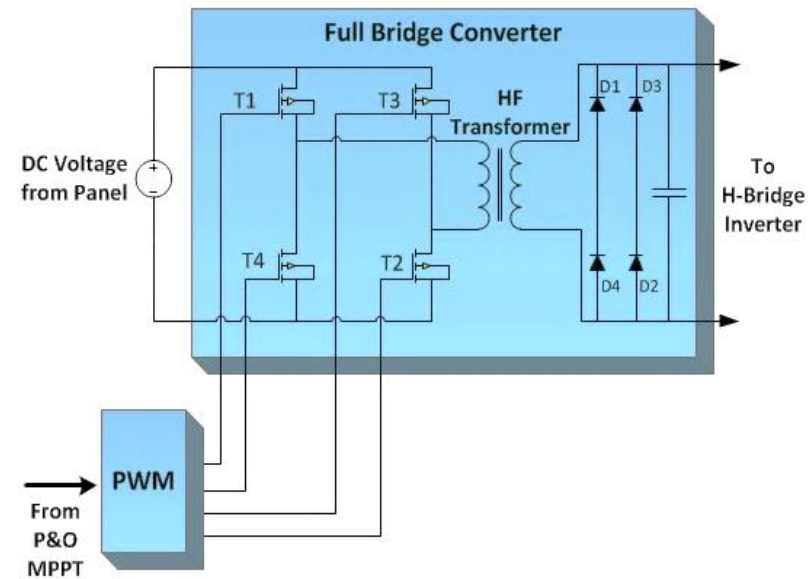

Fig 5: Full Bridge converter

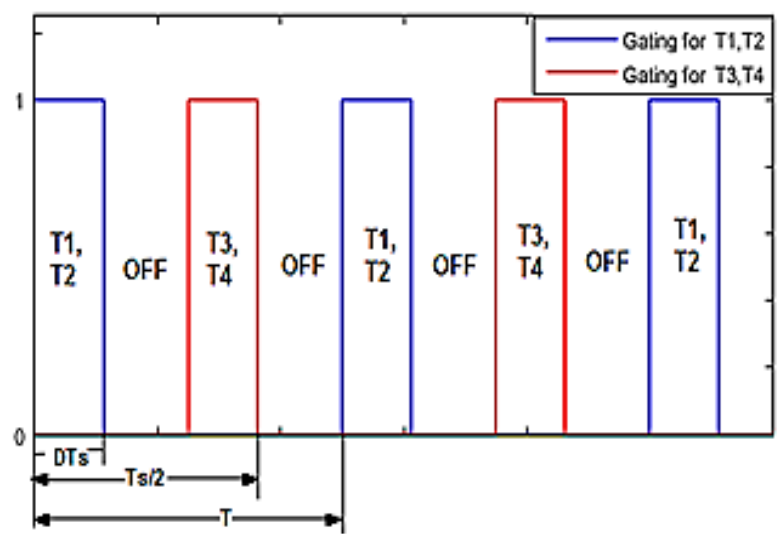

Fig 6: PWMGating Pulses for Full Bridge converter

If the output power of the PV Panel increases, the next The gating pulses to the full bridge converter are as shown perturbation is kept in the same direction. If the in fig 6 . The total switching time is $\mathrm{T}$. At interval 0 to perturbation causes a reduction in power, then the sign DTs, the switches T1 and T2 are turned on. The current next perturbation will be opposite. Based on these facts, through the transformer primary is positive hence positive the algorithm is implemented as shown in the flowchart in voltage is produced at the secondary. A zero signal is Fig.4.This process is repeated until the peak power point is followed after the interval DTs during which all the 


\author{
National Conference on Advances in Electrical Engineering \\ NMAM Institute of Technology, Nitte \\ Vol. 5, Special Issue 2, April 2017
}

switches are off. After the zero signal interval, switches T3 and T4 are turned on up to interval Ts/2. During this interval, the current through the transformer primary is negative as a result negative output voltage is produced at the secondary. Again, a zero signal is followed after the interval Ts/2 to T during which all the switches are off.

The diode bridge is connected across the secondary winding of the High-frequency step-up transformer. It consists of four diodes and converts the stepped-up AC voltage pulses into smooth DC Voltage. Full wave diode bridges have better performance and low voltage stress per component compared to half wave bridge rectifiers. A filter capacitor is usually connected in parallel with the Diode Bridge to reduce the output ripple.

\section{H-BridgeInverter}

H-Bridge inverter consists of four MOSFET switches which are connected in "H" shape to form a bridge. These switches are used to control the direction of current running from the DC source to the connected load in either direction. Hence it converts the input DC power into AC output power. The MOSFETs are switched from anSPWMgenerating circuit to get nearly sine wave AC output. The switching frequency of the switches is equal to the mains AC supply frequency $(50 \mathrm{~Hz}$ in this case).

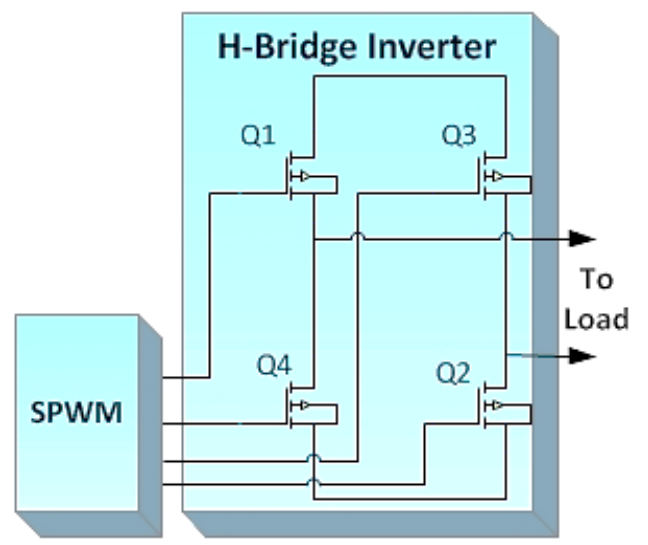

Fig 7: H-Bridge Inverter with SPWM control

\section{E. Sinusoidal Pulse Width Modulation}

In this simulation, SPWM is used to generate sine wave output from DC input. SPWM technique is characterized by constant amplitude pulse with varying duty cycle for each period. To generate SPWM signals, a high-frequency triangular wave is used as carrier signal ( $\mathrm{Vt}$ ), which is compared with sinusoidal waves $(\mathrm{V} \sin (\mathrm{x})$ and $\mathrm{Vsin}$ $(180+x))$ which are $180^{\circ}$ out of phase with each other. The resulted signal is called the reference signal (Vr). This signal is then provided to the switches of the H-Bridge inverter. Here unipolar SPWM technique is used.

The most important parameter of designing the switching strategy is amplitude modulation $\left(\mathrm{M}_{\mathrm{A}}\right)$ that will influence the performance of the inverter. $\mathrm{M}_{\mathrm{A}}$ is defined as the ratio of the magnitudes between sine waveform (reference signal) and the triangular waveform (carrier signal). The amplitude modulation is determined by the following equation:

$$
\mathrm{M}_{\mathrm{A}}=\frac{\mathrm{V}_{\mathrm{r}}}{\mathrm{V}_{\mathrm{c}}}
$$

Usually, the value of $\mathrm{M}_{\mathrm{A}}$ is chosen between 0.8 and 0.9. If $\mathrm{M}_{\mathrm{A}}$ is greater than 1 , there will be more harmonics at the output.This condition is known as over modulation and should be avoided. Fig 8 illustrates the unipolar SPWM Technique.
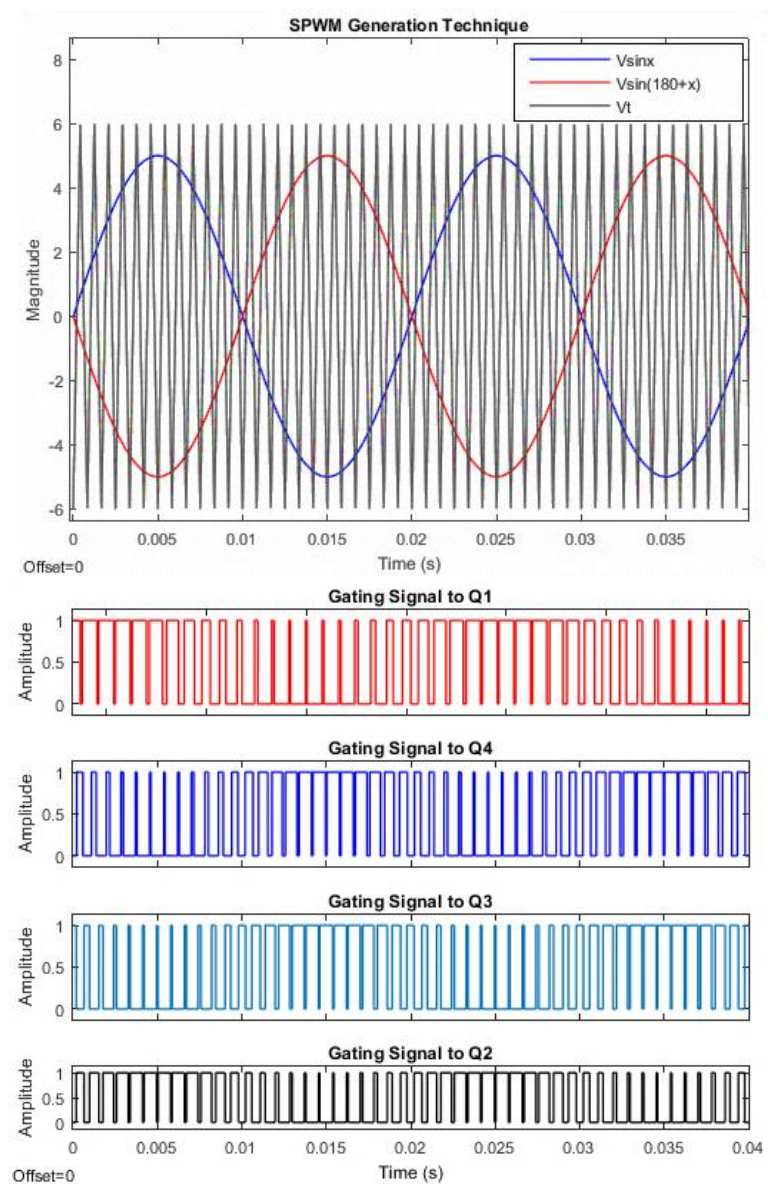

Fig 8: SPWM generating technique gating pulses to $\mathrm{H}$ Bridge Inverter

\section{F. Filter Circuit}

The filter circuit in this inverter consists of an LC circuit which reduces the output harmonics thus reducing THD. Since SPWM technique is used, the filtering requirement is fairly less. The filter inductor $\left(\mathrm{L}_{\mathrm{f}}\right)$ and the filter capacitor $\left(\mathrm{C}_{\mathrm{f}}\right)$ are designed so that the cut-off frequency $\left(f_{c}\right)$ is $75 \mathrm{~Hz}$ which is greater than $50 \mathrm{~Hz}$ but much less than harmonic frequency. The $\mathrm{L}_{\mathrm{f}}$ and $\mathrm{C}_{\mathrm{f}}$ Values are determined by the formula:

$$
f_{c}=\frac{1}{2 \pi \sqrt{L_{f} C_{f}}}
$$




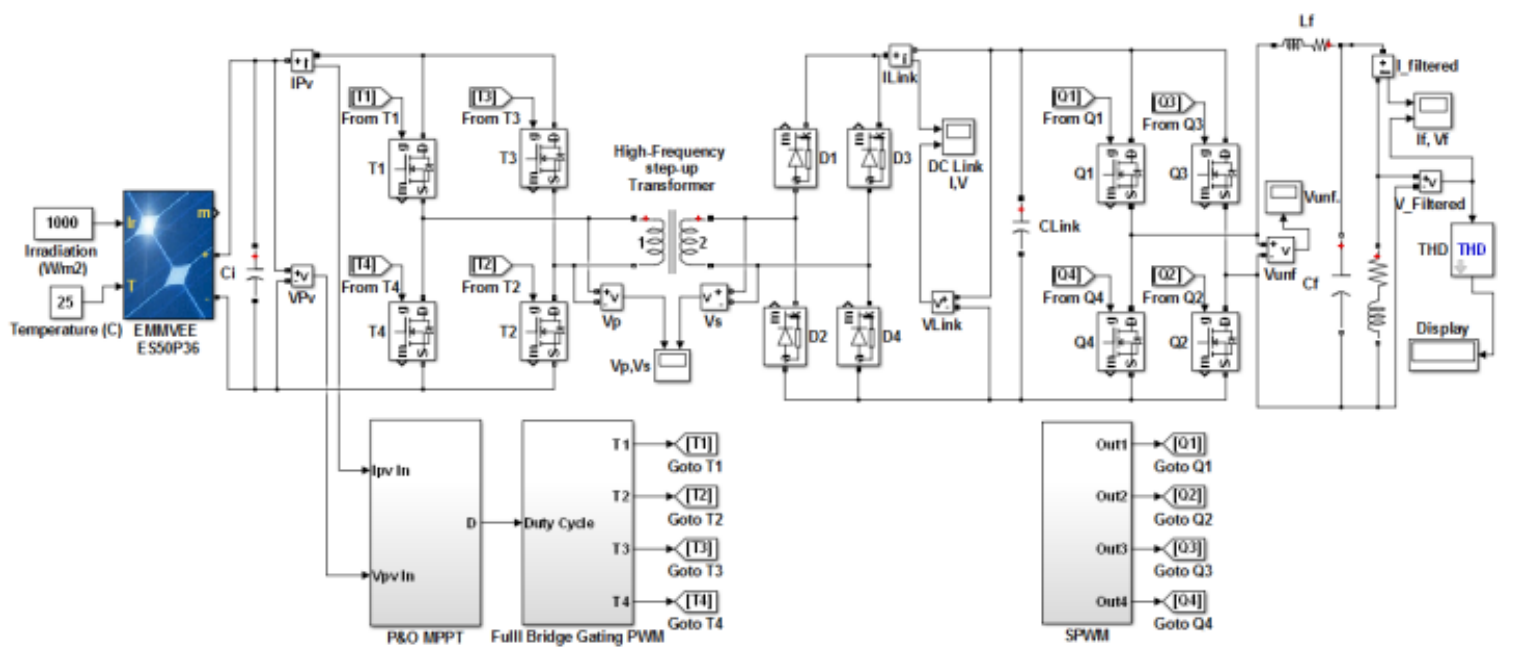

Fig 9: MATLAB Model of Single phase PV inverter with Full Bridge converter

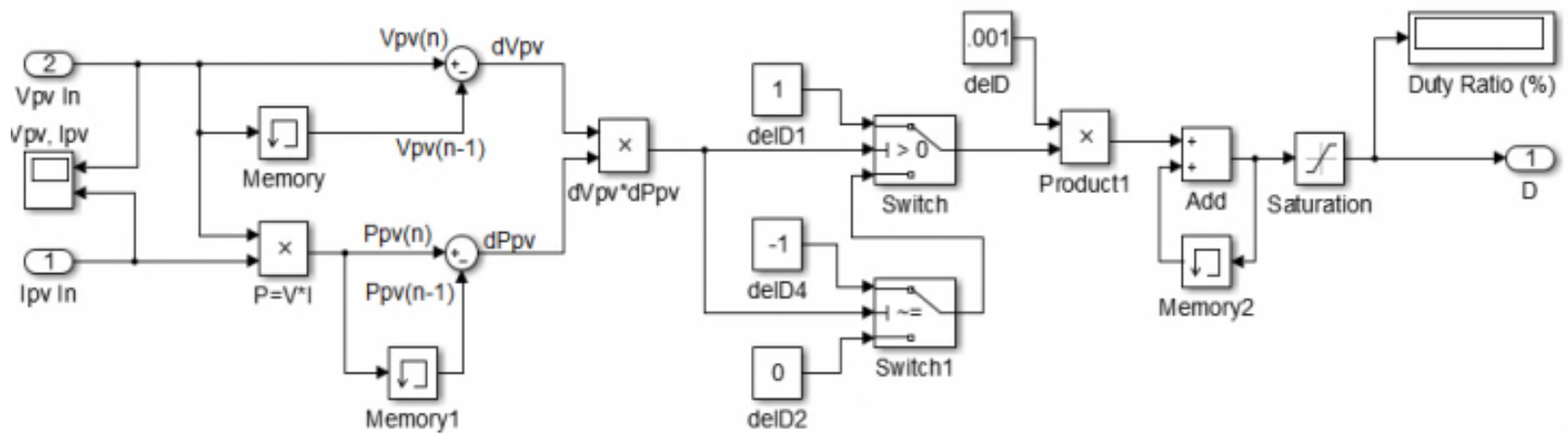

Fig 10: Perturb and Observe MPPT Implementation in MATLAB/Simulink

\section{SIMULATION STUDIES} The single-phase H-bridge inverter is simulated using and H-Bridge inverter respectively. The output of the MATLAB/Simulink software. Fig. 9 shows the schematic inverter contains harmonics which is filtered by the LC diagram of Single-phase PV inverter with Full Bridge filter circuit. Thusa pure sinusoidal voltage waveform is converter system implementation in MATLAB. The produced at the output. transformer and the PV panel data is directly entered to the simulator.

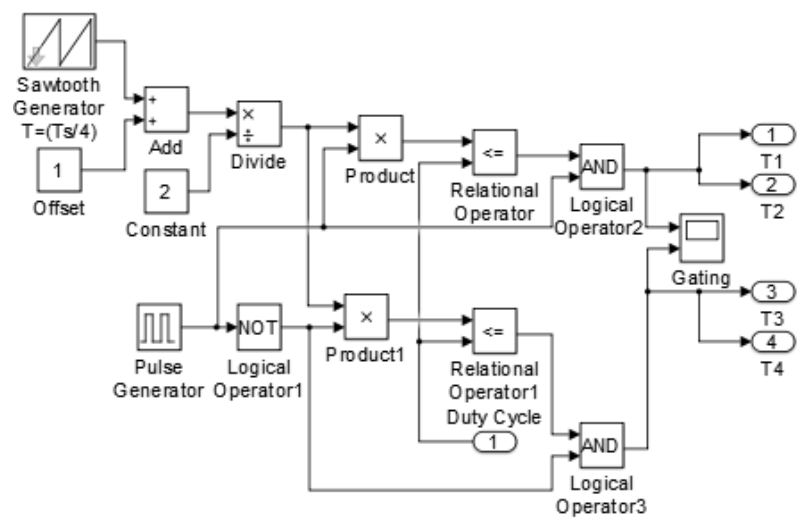

Fig 11: Calculation of duty cycle from P\&O MPPT

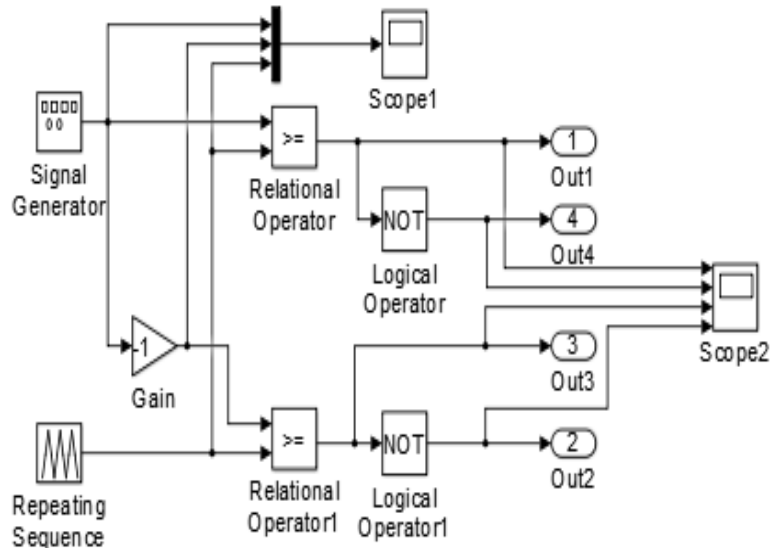

Fig 12 SPWM Subsystem 
National Conference on Advances in Electrical Engineering

\section{WAVEFORMS}

The Circuit is simulated in the MATLAB/Simulink Software and the output is obtained. Fig 13 shows the current drawn from the PV Panel and thevoltage across the PV Panel. The voltage across primary and secondary windings of the transformer is as shown in fig 14.The DC link voltage and current in between the converter and inverter are shown in fig 15 . Fig 16 shows unfiltered output voltage and fig 17 shows the filtered voltage and current at the output load side of the inverter.
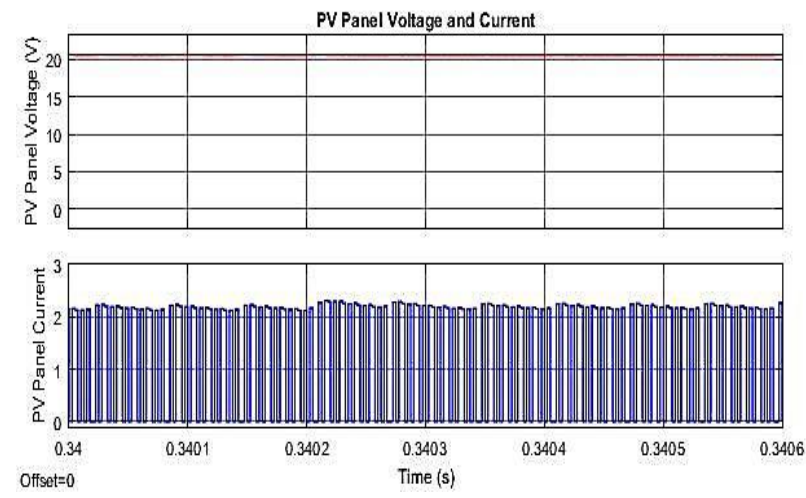

Fig 13: PV Panel Voltage and Current

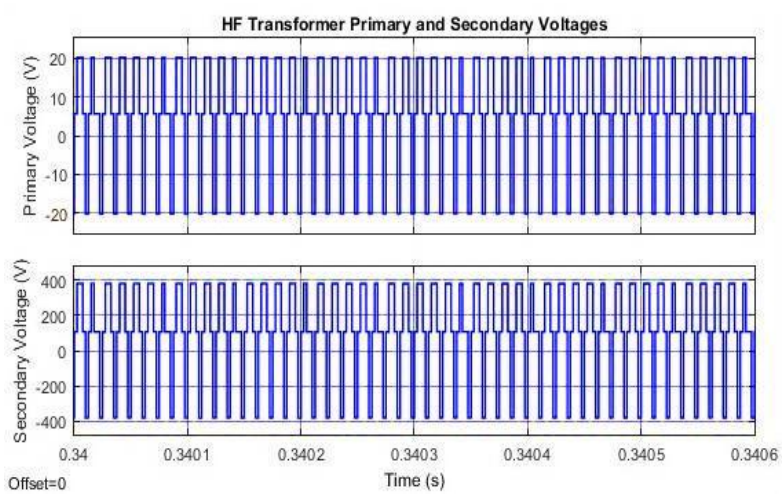

Fig 14: Primary and Secondary Voltages of HF step-up Transformer
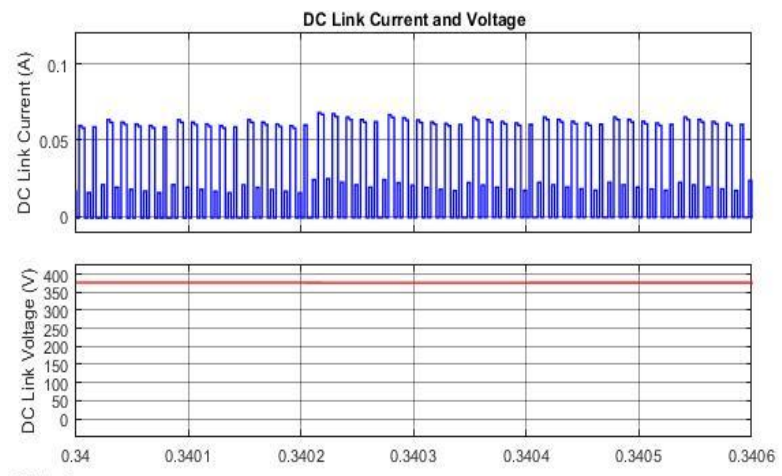

Fig 15: DC link voltage and current in between the converter

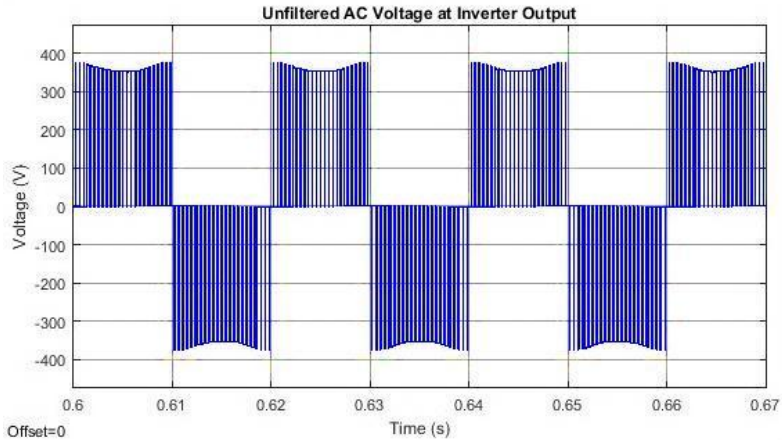

Fig 16: Unfiltered AC Voltage at Inverter Output

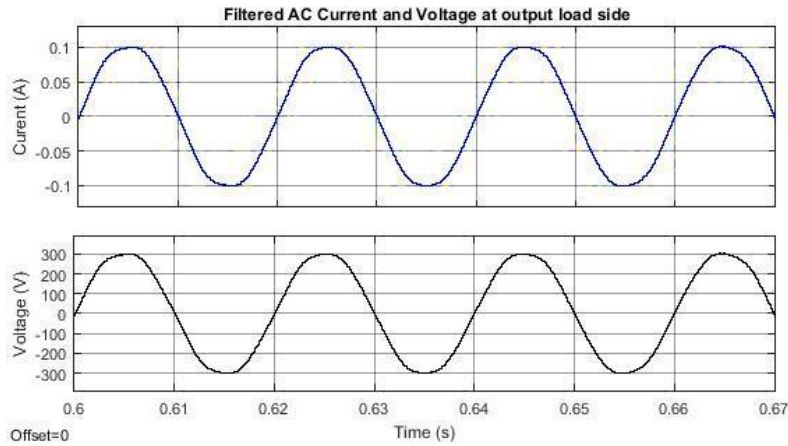

Fig 17: Unfiltered AC Voltage at Inverter Output

\section{CONCLUSION}

This paper presents the design and simulation of a pure sine wave inverter for photovoltaic applications. Various advantages exist in the proposed system such as low switching loss, high efficiency, low cost, galvanic isolationbetween converter and inverter side and small size.

Simulation of this inverter shows that power from PV array can be converted to thepure sine wave output voltage and the fundamental harmonic component lies at $50 \mathrm{~Hz}$ and higher harmonic components are completely eliminated. Thus it can be concluded that this sine wave inverter is ideal for the photovoltaic power systems.

\section{ACKNOWLEDGMENT}

I would like to express my sincere gratitude and thanks to Dr. Nagesh Prabhu, HOD, Electrical and Electronics Engineering Dept., Nitte and my project Guide, Ms. Swathi Hatwar, Asst. Professor of Electrical and Electronics Engineering, for all the guidance, encouragement and support.

\section{REFERENCES}

[1] Ahmed Sony Kamal Chowdhury, M. Shamir Shehab, M. Abdul Awal, M. Abdur Razzak "Design and Implementation of a Highly Efficient Pure Sine-Wave Inverter for Photovoltaic 
Vol. 5, Special Issue 2, April 2017

Applications"2013 International Conference on Informatics, Electronics and Vision (ICIEV)pp.1-6

[2] T. K. Kwang, S. Masri, "Single phase grid tie inverter for photovoltaic application," Proc. IEEE Sustainable Utilization and Development in Engineering and Technology, pp. 23-28. Nov 2010.

[3] H. Dehbonei, L. J. Borle, "Design and implementation of a low-cost sine wave inverter," IEEE, 2003, pp. 280-285.

[4] Oladimeji Ibrahim; Nor Zaihar Yahaya; Nordin Saad; Muhammad Wasif Umar "Matlab/Simulink model of solar PV array with perturb and observe MPPT for maximizing PV array efficiency" IEEE Conference on Energy Conversion (CENCON) pp. 254-258, 2015

[5] Fahad Rasool, Micheal Drieberg, Nasreen Badruddin and Balbir Singh Mahinder Singh "Modeling of PV panels performance based on datasheet values for solar micro energy harvesting" 2016 6th International Conference on Intelligent and Advanced Systems (ICIAS) pp.1-5

[6] "Power Electronics for Photovoltaic Power Systems" Mahinda Vilathgamuwa, Dulika Nayanasiri, Shantha Gamini. Synthesis Lectures on Power Electronics IEEE Publication. Morgan \& Claypool publishers 2015

[7] N. Mohan, T. M. Undeland, \& W. Robbins, Power Electronics, 3rd ed., Denvers, MA: John Wiley \& Sons, Inc., 2006, pp. 211-214.

[8] M. H. Rashid, Power Electronics, Circuits, Devices, and Applications, 3rd Ed. New Delhi: Prentice-Hall, 2007 pp. 253-256.

[9] FAIRCHILD Semiconductors - Renewable EnergySolutions Energy Efficient Components For PV Solar Systems 